\title{
Psychiatric disorders after surgery for duodenal ulcer
}

\author{
M. C. MASON AND C. G. CLARK \\ From the Departments of Surgery, University of Leeds, and University College Hospital Medical School, \\ London
}

SUMmARY A prospective trial was conducted to determine the relationship between personality type and the results of surgery for peptic ulcer. Previous investigations had suggested that patients with an obsessional personality fared less well than those who were not obsessional. However, although there was a high incidence of psychiatric disorders in these surgical patients no significant difference was found between the two groups. It was concluded that classifying patients as obsessional and non-obsessional did not have any bearing on the outcome of operation.

The psychosomatic theory of the aetiology of duodenal ulcer probably stems from the observations of Beaumont (1833) who studied the gastric mucosa through a gunshot wound fistula in his patient Alexis St. John. The marked changes in the vascularity and secretion of the stomach found in response to induced changes in mood provided direct evidence that an association existed. Attempts to extend these observations to the aetiology of peptic ulcer, however, have met with little success (Roth, 1955; Kessel and Munro, 1964). Although no evidence has been found to support a psychosomatic cause for duodenal ulcer the relationship between psychological factors and the results of surgery show some interdependence (Pascal, Thoroughman, Jarvis, and Jenkins, 1966; Glen and Cox, 1968) and this may have a bearing on selecting suitable cases for operation. Sinclair-Gieben, Clark, and Dean (1962), in a retrospective study, found that patients with an obsessional personality were more liable to psychiatric breakdown if their ulcer symptoms were relieved by operation. This finding was so remarkable that a prospective study was begun in 1962 . Sufficient time has now elapsed to assess the results.

\section{Methods}

A series of 100 patients admitted to hospital for elective surgery for duodenal ulcer were examined by a psychiatrist. An objective rating scale based on the Minnesota multiphasic personality inventory was used, principally to determine aspects of mood, and personality was determined by specific questions (Sinclair-Gieben et al, 1962) modelled on Schneider's (1958) concept of anencastic personality. On this basis the patients were allocated either to an 'obsessional' or 'nonobsessional' group. Where there was doubt the patient was regarded as non-obsessional. These ratings, together with the comments of the psychiatrist, were not seen by the surgeon performing the operation, and were filed away until the final assessment some years later.

The operations performed were vagotomy with gastroenterostomy, either ante-colic or retrocolic, in all but two cases where a pyloroplasty was performed. An attempt was made to see these patients in 1967, an average of four to five years after operation. The results of surgery were then examined in relation to the psychological grading. A note was made of any treat- 
ment for psychiatric disturbance since operation and since the patients were drawn from an area with a central records system, this could be confirmed. In particular information was available about attempted suicide.

In the intervening years a number of patients had further investigations performed because of residual symptoms. Some of these were submitted to further surgery, but it should be emphasized that psychiatric assessment was not carried out as part of the investigations or in reaching a decision to perform a second operation.

\section{Results}

The details of age, sex, duration of symptoms, and age at operation are shown for the two groups of patients in Table I. Seven patients died in the interval between operation and review and one patient was untraced. Seven patients could not

\begin{tabular}{lll}
\hline & Obsessional & Non-Obsessional \\
\hline $\begin{array}{lll}\text { No. entered in trial } \\
\text { Ratio (males/females) }\end{array}$ & 52 & 48 \\
Mean age at onset of & $36 / 16$ & $38 / 10$ \\
$\quad$ symptoms (yr) & $30 \cdot 0 \pm 1 \cdot 4$ S.E. & $28 \cdot 8 \pm 1 \cdot 4$ S.E. \\
$\begin{array}{l}\text { Mean age at operation (yr) } \\
\text { Mean duration of }\end{array}$ & $45 \cdot 8 \pm 1 \cdot 6$ S.E. & $43 \cdot 6 \pm 1 \cdot 8$ S.E. \\
$\quad$ symptoms (yr) & $15 \cdot 7 \pm 1 \cdot 3$ S.E. & $14 \cdot 8 \pm 1 \cdot 5$ S.E. \\
Died & 3 & 4 \\
Untraced & - & 1 \\
Questionnaire & 6 & 1 \\
Available for interview & 43 & 42 \\
\hline
\end{tabular}

Table I Details of the patients in the two groups

\begin{tabular}{|c|c|c|c|c|}
\hline & Obsessional & & Non-Obsess & sional \\
\hline Excellent & $25(51 \%)]$ & & $28(65 \%)$ & \\
\hline $\begin{array}{l}\text { Good } \\
\text { Poor }\end{array}$ & $\begin{array}{r}14(28 \%) \\
6(12 \%)\end{array}$ & & $\begin{array}{l}6(14 \%) \\
5(11 \%)\end{array}$ & \\
\hline Definite recurrent ulcer & 0 & $20 \%$ & $2(4.5 \%)$ & $20 \%$ \\
\hline Suspected recurrent ulcer & $4(8 \%)$ & & $2(4.5 \%)$ & \\
\hline
\end{tabular}

Table II Comparison of results in two groups of patients $^{1}$

${ }^{1}$ There is no statistical significance in the comparisons or when the patients are classified as satisfactory (excellent and good results) or unsatisfactory (the remainder).

\begin{tabular}{lll}
\hline & Obsessional & Non-Obsessional \\
\hline No. with further surgery & 3 & 8 \\
Psychiatric treatment & 4 & 6 \\
Attempted suicide & 1 & 3
\end{tabular}

Table III Frequency of second operations and of psychiatric symptoms in the two groups attend for interview but replied to a questionnaire on which a reasonable estimate of the results of surgery could be based. There is good comparison between the obsessional and nonobsessional groups and the results of surgery are shown in Table II, according to a classification used in another study (Mason and Clark, 1969). The excellent results are in those who are symptom free and good results are in those who have no dyspeptic symptoms but some minor disability from the operation such as dumping or diarrhoea. Poor results represent those patients with severe postoperative disability but can be distinguished from those whose symptoms suggest recurrent ulceration. The latter classification can be subdivided according to whether the recurrent ulcer is demonstrated (radiologically, gastroscopically, or at operation) or is merely 'suspected' on the basis of symptoms. It is evident (Table II) that there is no real difference in the late results of surgery in these two groups, and indeed when these are broadly classified as satisfactory results (excellent and good) and unsatisfactory results (the remainder) the results are identical.

A comparison of the number of further operations performed and the incidence of psychiatric disturbance requiring treatment or attempts at suicide is shown in Table III, where it can be seen that the incidence of these complications is almost twice as great in the non-obsessional compared with the obsessional group.

\section{Discussion}

The results of surgery for duodenal ulcer are generally satisfactory. In every series, however, there is a group of patients with poor results due either to recurrent ulceration or to the various syndromes often classified as 'post-gastrectomy syndromes' but which can occur after any type of gastric operation used in this disease. Some of these patients with poor results can be treated satisfactorily by various types of gastric reconstructive operations, implying that faulty surgery is responsible for some of the bad results, but a number do not respond. The difficulties inherent in selection for further surgery in these patients have already been discussed (Buchan, Clark, and Downie, 1965) but there is a tendency for many surgeons to regard the bad results of surgery as a defect inherent in the patient rather than in the operation. Thoroughman (1963) has examined this problem, and, using psychological techniques and a scoring system, he has made predictions of the outcome of operation in a prospective study which shows a significant relationship with the results of surgery (Pascal et al, 1966).

The present investigation was based on the conclusions of a retrospective study which appeared to show that the results of operation were 
less satisfactory in patients with an obsessional trait (Sinclair-Gieben et al, 1962). A hypothesis was considered that the obsessional patient was in some way dependent on his ulcer symptoms and consequently if his symptoms were relieved by operation he would be prone to psychiatric illness. The defect of this original observation was that observer bias was introduced, since the psychiatrist who had advanced the hypothesis was responsible for the assessment of obsessional personality and any psychiatric illness, on the basis of an interview. It was therefore essential to test the theory by a prospective trial. Whereas the classification of personality has many defects, there is less criticism of a simple division into obsessional and non-obsessional types. This assessment was made before operation and to obviate bias the psychiatrist's assessment was kept apart from the subsequent notes used at follow up. Patients seen at the gastric follow-up clinic were assessed by surgeons purely on the basis of physical symptoms, and referrals for any subsequent psychiatric assessment were usually made by the general practitioner. Suicide by means of barbiturates was attempted in four patients but we have evidence that all late deaths were due to organic disease.

If the obsessional patient is in some way dependent on his ulcer, then the hypothesis suggests that there should be either a higher incidence of poor and unsatisfactory results in this group or alternatively that the frequency of psychiatric disorders should be greater in this group. That neither of these postulates is supported can be seen from Tables II and III. The frequency of poor surgical results is identical in the two groups of patients, and the incidence of postoperative psychiatric disorders and attempted suicide is greater in the non-obsessional patients. Furthermore, though second operations were generally performed for reasons related to initial surgery (recurrent ulcer, hiatus hernia, conversion of gastroenterostomy to pyloroplasty, and adhesions), again the frequency of these is greatest in the non-obsessional patients.

The type of psychiatric disturbance most commonly encountered in these patients was depression. This has been noted by others (Glen and Cox, 1968) and was the most frequent complication found in the original study (Sinclair-Gieben et al, 1962). In the previous study, however, it appeared to be confined to obsessional patients but this has not been borne out by the present investigation. In the early study patients with partial gastrectomy and patients with perforated peptic ulcer formed the study group, and the inclusion of the latter may have introduced some errors. The present study was confined to patients treated by vagotomy and gastroenterostomy (two patients with pyloroplasty) but there is no difference in the incidence of unsatisfactory surgical results between this operation and partial gastrectomy (Glen and Cox, 1968). It can be concluded that the results of surgery for duodenal ulcer in patients with an obsessional personality are in no way inferior to the results in other patients. This method of trying to predict the results of surgery or of identifying a group likely to require psychiatric supervision has not proved reliable. Nevertheless the frequency of psychiatric referral $(11 \%)$ and the incidence of attempted suicide $(4 \%)$ in these patients over a period of five years suggests that follow up of patients treated by gastric surgery should concern itself with psychiatric disturbance.

\section{References}

Beaumont, W. (1833). Experiments and Observations on the Gastric Juice and the Physiology of Digestion. F. P. Allen, Plattsburg, New York.

Buchan, R., Clark, C. G., and Downie, R. W. M. (1965). Conversion to Billroth-I anastomosis or enteroanastomosis for postgastrectomy states. Brit. J. Surg., 52, 651-657.

Glen, A. I. M., and Cox, A. G. (1968). Psychological factors, operative procedures, and results of surgery for duodenal ulcer. Gut, 9, 667-671.

Kessel, N., and Munro, A. (1964). Epidemiological studies in psychosomatic medicine. J. Psychosom. Res., 8, 67-81.

Mason, M. C., and Clark, C. G. (1969). Surgery for duodenal ulcer. Brit. J. Surg., 50, 815-817.

Pascal, G. R., Thoroughman, J. C., Jarvis, J. R., and Jenkins, W. O. (1966). Early history variables in predicting surgical success for intractable duodenal ulcer patients. Psychosom. Med., 28, 207-215.

Roth, H. P. (1955). The peptic ulcer personality. Arch. intern. Med., 96, 32-43.

Schneider, K. (1958). Psychopathic Personalities, translated by M. W. Hamilton from 9th German ed., p. 88. Cassell, London.

Sinclair-Gieben, A. H. C., Clark, C. G., and Dean, A. C. B. (1962). Psychiatric illness following surgery for duodenal ulcer. Scot. med. J., 7, 168-172.

Thoroughman, J. C. (1963). Surgery and the patient with intractable peptic ulcer. Amer. J. Surg., 105, 334-337. 